\title{
Modeling of Capillary Discharge Plasma for X-Ray Lasers, XUV Lithography and Other Applications
}

\author{
V.N. Shlyaptsev, J. Dunn, S.J. Moon, K.B. Fournier, \\ A.L. Osterheld, J.J. Rocca, J. Filevich, M. Marconi, E. Jankowska, \\ E.C. Hammarsten, S. Sakadzic, A. Rahman, M. Frati, F.G. Tomasel, \\ N. Fornaciari, D. Buchenauer, H.A. Bender, S. Karim, M. Kanouff, J. Dimkoff, \\ G. Kubiak, G. Shimkaveg and W.T. Silfvast
}

U.S. Department of Energy

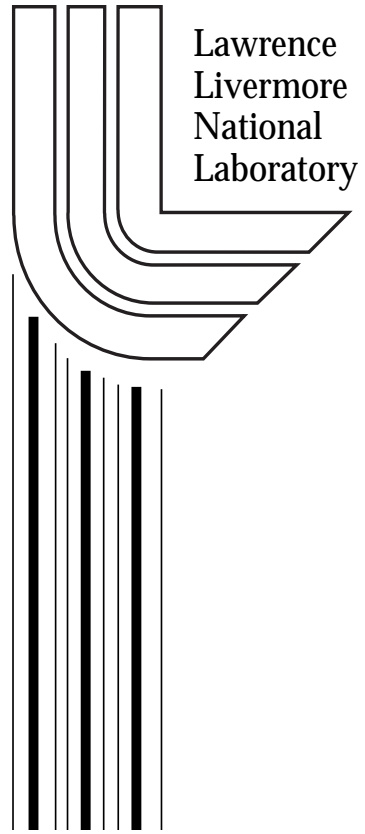

This article was submitted to:

5-th International Conference on Dense Z-pinches, Albuquerque, NM, June 23 - 28, 2002

October 22, 2002 


\section{DISCLAIMER}

This document was prepared as an account of work sponsored by an agency of the United States Government. Neither the United States Government nor the University of California nor any of their employees, makes any warranty, express or implied, or assumes any legal liability or responsibility for the accuracy, completeness, or usefulness of any information, apparatus, product, or process disclosed, or represents that its use would not infringe privately owned rights. Reference herein to any specific commercial product, process, or service by trade name, trademark, manufacturer, or otherwise, does not necessarily constitute or imply its endorsement, recommendation, or favoring by the United States Government or the University of California. The views and opinions of authors expressed herein do not necessarily state or reflect those of the United States Government or the University of California, and shall not be used for advertising or product endorsement purposes.

This is a preprint of a paper intended for publication in a journal or proceedings. Since changes may be made before publication, this preprint is made available with the understanding that it will not be cited or reproduced without the permission of the author. 


\title{
Modeling of Capillary Discharge Plasma for X-ray lasers, XUV Lithography and other Applications
}

\author{
V.N.Shlyaptsev', J.Dunn'2, S.J. Moon ${ }^{2}$, K.B.Fournier, A.L.Osterheld ${ }^{2}$, \\ ${ }^{1}$ UC Davis-Livermore, LLNL, Livermore, CA, 94551 \\ ${ }^{2} L L N L$, Livermore, CA, 94550,
}

J.J.Rocca, J.Filevich, M.Marconi, E. Jankowska, E. C. Hammarsten, S. Sakadzic, A. Rahman, M. Frati, F.G. Tomasel, Colorado State University, Ft.Collins, CO, 80523

\author{
N.Fornaciari, D.Buchenauer, H.A.Bender, S.Karim, \\ M.Kanouff, J.Dimkoff, G.Kubiak, \\ Sandia National Labs, Livermore, CA, 94551 \\ G.Shimkaveg, W.T.Silfvast \\ School of Optics/CREOL, University of Central Florida, Orlando FL 32816-2700
}

It is long ago recognized that Z-pinches represent very natural medium for $\mathrm{x}$-ray lasers (XRL) due to its favorable geometry and achievable high densities and temperatures. They also are very efficient $\mathrm{x}$-ray sources. One of their variants, the capillary discharges, attracted attention of plasma physics researchers for almost two decades. It has been used for hot dense plasma formation and x-ray lasers[1,2], for transportation of laser beams and XUV radiation generation in x-ray lithography[3,4], for basic Z-pinch research and some others. The combination of efficiency, simplicity and low cost of capillary electrical discharges allowed to scale capillary $\mathrm{x}$-ray lasers to table-top dimensions. In this paper we show the modeling results for next, 3-4 times shorter wavelength x-ray lasers.

As an efficient $\mathrm{x}$-ray source of line and continuum radiation it can be used for many practically important application in science and technology. In particular, the capillary discharge can appear as powerful potential candidate for emerging XUV microlithography. We present here the results of numerical modeling of spectra and density of Xe EUV source which involved plasma heating and dynamics, detailed atomic kinetics and radiation transport and material ablation physics.

\section{CAPILLARY DISCHARGE X-RAY LASERS AND APPLICATIONS}

During last decade has been made substantial progress in parameters of materials and drivers for capillary discharges which are able to reach electric currents of 200KA in risetime of about $10 \mathrm{~ns}$. It allowed to reach electron temperatures up to $500 \mathrm{eV}$, densities (1-3) $10^{20} \mathrm{~cm}^{-3}$, 300 times density compression ratios, $1 \mathrm{~mJ}$ of XRL energy per pulse, high-rep rate of operation, table-top dimensions. Last its quality represented the major goal of XRL development during these years because it makes them affordable for many different applications. Utilized right now mostly for scientific applications, they are already expanding many traditional scientific methods allowing to extract more detailed information with better accuracy. Among such applications are 
- Shadowgraphy. Capillary $\mathrm{x}$-ray laser can be used for shadowgraphy due to its very large peak brightness of the order of $10^{25} \mathrm{ph} . \mathrm{mm}^{-2} \mathrm{mrad}^{-2} \mathrm{~s}^{-1}(0.1 \% \mathrm{BW})^{-1}$. The modeling and the shadowgraphy experiments with argon $46.9 \mathrm{~nm}$ capillary $\mathrm{x}$-ray laser radiation passing through elongated plasma formed with driving current via another capillary was done in this work [5]. Same kind of setup can in principle be applied for diagnostics of NIF hohlraum and other fusion experiments. It is also important that this method has exponential sensitivity because of exponential dependence of transparency on absorption coefficients.

- Soft x-ray imaging. The images of plasma in different regions of spectra for wide range of currents and initial plasma diameters sizes, for gas-, vapor-filled or evacuated capillaries were obtained in numerous experiments. Specifically interesting was near- and far-field imaging of output characteristics of capillary x-ray laser. In this case experiments and its numerical modeling allow to reveal detailed data on plasma evolution and amplification dynamics because, as with shadowgraphy, this method of diagnostics also has exponential sensitivity (this time on gain instead of absorption coefficient) [6].

- Spectroscopy. It is primary and widely used method, but combined with x-ray lasers the spectroscopy can demonstrate exponential sensitivity via influence of different factors on linewidth and hence gain. It can be used not only for temperature and density diagnostics of plasma column, evaluate amplification of x-ray laser etc but also to find extremely weak plasma processes like Zeeman effect [7] or isotopic hyperfine splitting in spectral lines [8].

- Interferometry. The interferometry promise to be the key most important application of $x$ ray lasers because it utilizes their unique property of coherency. Recently the plasma interferometry with capillary XRL was demonstrated which then has been used for plasma

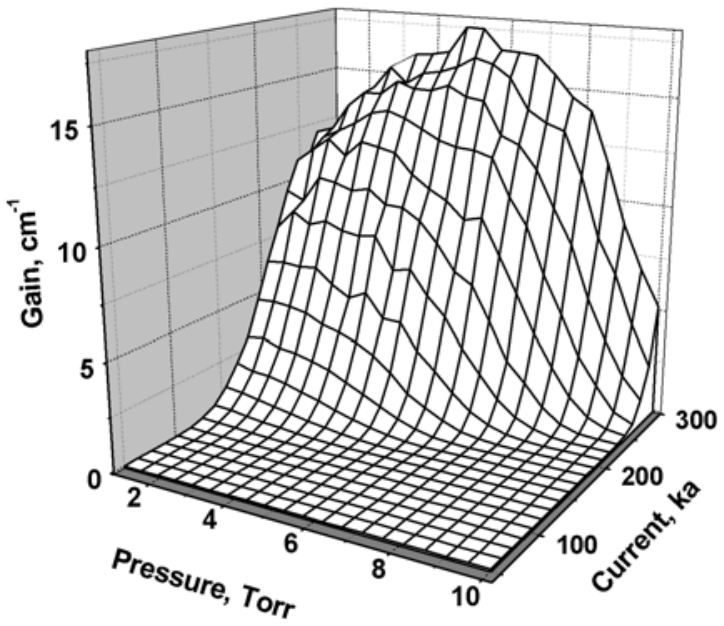

Fig. 1 Small signal gain on $4 \mathrm{~d}-4 \mathrm{p}$ transitions in Nilike $\mathrm{AgXX}$ as a function of current and pressure. This RADEX optimization data was obtained with over 400 hydro/atomic kinetics runs. diagnostics applications [9]. Already first such experiments allowed to observe unexpected 2D features not seen before of laser produced plasma used as an object for this probing[10]. Combined with high brightness of capillary lasers, the interferometry will bring incredible precision to applications in material science, $x$-ray holography, metrology and fusion applications. So, with capillary XRL we got in our hands extremely powerful and sensitive diagnostic tool with great potential in many future applications.

Substantial experimental and theoretical efforts are now devoted to extend this kind of XRL to shorter wavelengths. The RADEX simulations and spectroscopic diagnostics experiments of plasma indicate that the electron density $\mathrm{N}_{\mathrm{e}}>10^{20} \mathrm{~cm}^{-3}$ and temperature $\mathrm{T}_{\mathrm{e}} \sim 200-400 \mathrm{eV}$ at higher currents $\sim 150-200 \mathrm{kA}$ can be achieved in capillary discharge of high-Z plasma[2,11]. At such temperatures and densities the collisional XRL scheme on Ni-like ions can work particularly 
well. The atomic elements suitable for lasing are in the range $A=42-50$ which are lasing at wavelengths down to $\sim 100 \AA$. For Ni-like CdXXI, the gain is calculated $\sim 1-2 \mathrm{~cm}^{-1}$, which is in qualitative agreement with current experimental data [11]. Fig.1 shows the results of numerical calculations of small signal gain for Ni-like $\mathrm{AgXX}$ ions which is substantially larger than for $\mathrm{Cd}$. We plan the experiments with Ni-like AgXX and possibly PdXIX in near future.

\section{CAPILLARY DISCHARGE EUV SOURCE FOR MICROLITHOGRAPHY}

The sources for EUV lithography must satisfy the large amount of specific practical, technological and environmental requirements of complex processes of microchip production. Among the requirement are the achievement of efficient $x$-ray conversion in specific spectral range, high average power, pulse-to-pulse stability, large source lifetime etc. Extremely high spatial and temporal stability of capillary plasma (the jitter in radial position of dense plasma column can be 20 microns or less, comparable to laser plasma), the relatively large temperatures achievable with small currents, simplicity and efficiency attracted attention of researchers to capillary discharge as radiation source.

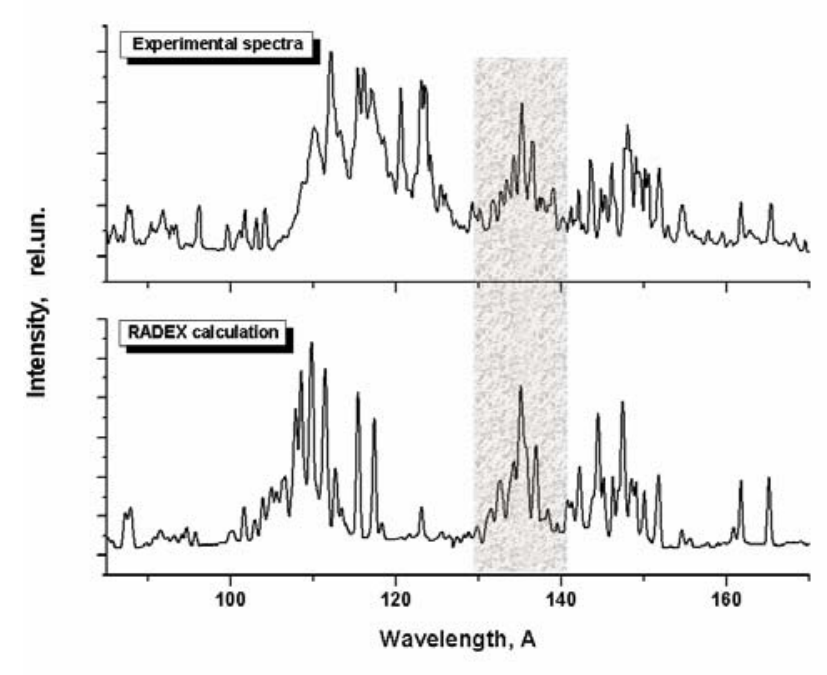

\begin{tabular}{l|l} 
XeVIII & 117A: 4p5s-g, 4p5p-g \\
\hline XeIX & 90A: 4d5f-g, 4d6p-g, \\
& 117A: 4d4f-g, \\
& 123A: 4p5s-4d5s \\
& 135A: 4p5s-4d5s, 4p5p- \\
& 4d5p, \\
& 145A: 4d4f-g, \\
& 163A: 4d5p-g \\
\hline XeX & 90A: 4d5f-g \\
& 110A: 4d4f-g, 4p4d-g, \\
& 145A: 4d5p-g, 4d4f-g \\
\hline XeXI & 80A: 4d5f-g, \\
& 110A: 4d4f-g, 4p4d-g, \\
& 135A: 4d5p-g, 4d4f-g, \\
& 4d5f-g
\end{tabular}

Fig. 2 The experimental (top) and code RADEX modeling spectra (bottom) of capillary discharge. The Table summarizes transitions which contribute to these spectra, " $\mathrm{g}$ " here denoted ground state(s)

The experiments with different capillary materials, currents and gas fills were performed in CREOL and Sandia National Labs $[4,12,13]$. For calculations of gas filled capillary discharge in Xe we use the same rad-MHD and atomic kinetics code RADEX developed for the x-ray laser modeling [1] but this time discharge was driven by much smaller 3-6kA and longer 1-2 $\mu \mathrm{s}$ currents pulses. The parameters of this discharge are somewhat intermediate between capillary XRL case and one of 300 micron microcapillary investigated previously in [5]. Both optical interferometry of capillary discharge plasma experiment performed at CREOL and RADEX simulations show that when current rises the electron density is reaching the maximum on axis due to Lorentz force and agrees well with value of density, the time it has been reached and its sharp increase near the wall. Still some disagreements also exist, specifically for cases of $\mathrm{Xe}+\mathrm{He}$ mixtures where inter-diffusion of separate components was 
neglected though code well predicts the temperatures and spectrum and hence ion composition in Xe+He mixtures.

Most computationally difficult in spectra calculations with high-Z gases like $\mathrm{Xe}$ is atomic kinetics and radiation transport. Just atomic data for several most abundant in our conditions ion stages XeVIII-XeXI is of the order of 1GB with number of atomic levels of the order of $10^{4}$ and lines approaching $10^{6}$. Main source of radiation in such systems is due to numerous often many fold overlapped atomic lines. The spectra obtained from $5 \mathrm{kA} 1.4 \mu \mathrm{s}$ diamond capillary discharge in Xe at 2 Torr in comparison with modeling spectra are shown in Fig.2. The table marks the major transitions contributing into different spectral bands. Some missing transitions in RADEX spectra around 120A are due to omission in the calculations of lower Z stages Xe V-VII radiating at much lower temperatures. The calculations done with wide range parameters clearly support the observations that Ru-like ions XeXI are major contributors into 135A region of interest for microlithography. Also falling into the same region are several $4 \mathrm{p} 5 \mathrm{~s}-4 \mathrm{~d} 5 \mathrm{~s}$ transitions of Pd-like ions XeIX and many weak $4 \mathrm{~d} 4 \mathrm{f}-4 \mathrm{~d}^{9}$ transitions of Rh-like ions XeX total contribution of which is relatively small. Neighboring strong clusters of transitions at 110A are of all XeVII - XeXII while at 145A spectra mostly belong to Rh-like ions XeX. Still further modeling work is needed for better understanding the dynamics of this source, to optimize its spectral power, heat and radiation load on the capillary walls etc

This work was performed under the auspices of the US Department of Energy by the University of California Lawrence Livermore National Laboratory under Contract No. W7405-Eng-48 and partially by DARPA grant DE-FG 03-00ER15084 and NSF.

\section{References}

1. J.J.Rocca, V.Shlyaptsev, F.G.Tomasel, O.D.Cortazar, D.Hartshorn, J.L.A.Chilla, Phys. Rev. Lett., 73, 2192 (1994).

2. J.J. Gonzalez, M. Frati, J.J.Rocca, V.N.Shlyaptsev, A.L.Osterheld, Phys.Rev.E 65(2), 026404 (2002)

3. Y.Ehrlich, C.Cohen, and A.Zigler, J.Krall, P.Sprangle, and E.Esarey, Phys. Rev. Lett. 77, 4186 (1996)

4. M.A. Klosner, H. Bender, W.T. Silfvast and J.J. Rocca, Optics Letters, 22, 34, (1997).

5. M.C. Marconi, C.H. Moreno, J.J.Rocca, V.N.Shlyaptsev and A.L.Osterheld. Physical Review E 62, 7209 (2000)

6. C.H.Moreno, M.C.Marconi, V.N.Shlyaptsev, B.R.Benware,C.D.Macchietto, J.L.A.Chilla, J.J.Rocca, A.L.Osterheld, Phys.Rev.A, 58(2), 1509 (1998)

7. F.G. Tomasel, V.N. Shlyaptsev and J.J. Rocca, Phys.Rev.A, 54 ,2474, (1996).

8. J.N.Nilsen, J.Koch, J.H.Scofield et al, Phys. Rev. Lett. 70, 3713 (1993).

9. J. Filevich, K. Kanizay, M.C. Marconi, J.L.A. Chilla, and J.J. Rocca. Optics Lett. 25, 356, (2000).

10. J. Filevich, J.J. Rocca, E. Jankowskaa, E.C. Hammarsten, M.C. Marconi, S.J. Moon, V.N. Shlyaptsev, submitted to Phys.Rev.Lett

11. S. Sakadzic, M. Frati , F.G.Tomasel, A.Rahman, J.J.Rocca, V.N. Shlyaptsev, Proc.SPIE, Vol.4505, “X-ray lasers and applications" , 134 (2001)

12. N.R.Fornaciari, H.Bender, D.Buchenauer, M.P.Kanouff, S.Karim, C.D.Moen, K.D.Stewart, W.T.Silfvast, G.M.Shimkaveg, Proc. SPIE Vol.4688, "Microlithography-2002" (in press).

13. J.Dimkoff, N.Fornaciari, D.Buchenauer, S.Karim and H.Bender, Proc.SPIE, Vol.4688, "Microlithography2002", Santa Clara (2002). 